\title{
Kilogram per Liter
}

National Cancer Institute

\section{Source}

National Cancer Institute. Kilogram per Liter. NCI Thesaurus. Code C64566.

A unit of mass concentration defined as the concentration of one kilogram of a substance in unit volume of the mixture equal to one liter. The concept also refers to the unit of mass density (volumic mass) defined as the density of substance which mass equal to one kilogram occupies the volume one liter. 